\title{
Maria Cândida Mendonça, uma autora de poemas breves para a infância*
}

\author{
Sara Reis da Silva \\ [Recibido, 2 febreiro 2018; aceptado, 4 abril 2018] \\ http://dx.doi.org/10.15304/bgl.52.4580
}

RESUMO Neste estudo, reflecte-se primeiramente acerca da relevância da História da Literatura, do esclarecimento de alguns dos seus 'pontos nodais' e do papel fundamental do seu conhecimento, co-relacionada com a Filologia, no âmbito de uma educação literária. De seguida, propõe-se uma revisitação e uma análise da produção literária integral de Maria Cândida Mendonça (19301997), procurando dilucidar o seu lugar na Literatura Portuguesa para a Infância. Autora de um conjunto relativamente restrito -mas interessante- de títulos, uns situados no domínio da narrativa/prosa e outros no da poesia, todos publicados com a chancela da Plátano Editora, em colecções que, à data de edição, possuíram um importante papel, Maria Cândida Mendonça é uma das autoras que lamentavelmente parece integrar o grupo das 'femmes oubliées' da literatura e das artes portuguesas.

PALAVRAS-CHAVE: História da Literatura, Literatura Portuguesa para a Infância, Maria Cândida Mendonça.

ABSTRACT This study firstly reflects the relevance of History of Literature, the clarification of its 'nodal points' and the main role of its knowledge, co-related with philology, in the scope of literary education. Then, it will be proposed a reappraisal and analysis of all Maria Cândida Mendonça's integral literary production (1930-1997), trying to elucidate her role in Portuguese Children's Literature. Author of a relatively short collection -but interesting- of titles, some of them in the narrative/prose field and others in the poetry one, but all published with Plátano Editora, in collections with an important role in the moment of their edition, Maria Cândida Mendonça is one of the authors who unfortunately seems to be a member of the group 'femmes oubliées' of the Portuguese literature and art.

KEYWORDS: History of Literature, Portuguese Children's Literature, Maria Cândida Mendonça.

* Por vontade expressa da sua autora, este texto encontra-se escrito em Português europeu e segue a norma anterior ao Acordo Ortográfico de 1990. 
Para a escritora Luisa Ducla Soares, que, durante muito tempo, solidaria e afectuosamente, esteve perto de Maria Cândida Mendonça.

\section{Introdução: algumas notas sobre História Literária}

A História da Literatura ou a História Literária resulta da inscrição dos produtos literários a partir de uma época ou, por outras palavras, da sua explicação e integração numa periodização. Na verdade, "entende os fatos literários como efeitos de causas determináveis -basicamente, a subjectividade dos autores, o meio físico-geográfico e os processos sociais [...]." (Souza, 2014: 55). No essencial, a História da Literatura tem, pois, por objecto o estudo da literatura entendida a partir de uma perspectiva cronológica (Equipo Glifo, 1998). Pretende oferecer uma ordenação histórica e cronológica dos principais acontecimentos relativos à literatura, que, reunidos, surgem dotados de uma unidade facilitadora de uma visão de conjunto das tendências, das correntes literárias e, naturalmente também, da produção literária dos autores que a integram.

Antoine Compagnon (2010: 13), por exemplo, no imprescindível ensaio Para que Serve a Literatura?, alia a História Literária e a Filologia, acentuando que ambas se dedicam "às obras no que estas têm de único e de singular, de irredutível e de circunstancial (um texto, um autor), ou, quando muito, de serial (um movimento, uma escola), e explicam-nas pelo contexto". A sua proposta assenta, portanto, declaradamente na reunião de 'dilemas', como alude, reunião esta, no seu entender, "imprescindível ao bem estar do estudo literário” (Compagnon, 2010: 17). Trata-se, em última instância, de um posicionamento consentâneo com paradigmas teórico-metodológicos alicerçados na interdependência das quatro disciplinas a partir das quais se articulam os Estudos Literários -Teoria, Crítica, História e Literatura Comparada-, uma conjugação apontada, por exemplo, por Darío Villanueva $(1994,2004)^{1}$. Com efeito, conforme estipula Aguiar e Silva, por exemplo, a literatura como "sistema semiótico, como instituição, como processo de produção e de leitura de textos constitui parte da fenomenologia histórica das sociedades humanas e das suas culturas" (Silva, 1990: 403). O campo literário reclama, tanto no

1 Esta perspectiva é convocada por Roig Rechou na introdução de História da Literatura Infantil e Xuvenil Galega (Xerais, 2015). 
plano do conhecimento teorético, como no plano de conhecimento histórico, a construção de uma 'periodização literária', isto é, de uma identificação, delimitação e caracterização de "fenómenos de homeostase e de homeorrese, de continuidade e de mudança na literatura como sistema semiótico, como instituição, como processo de produção e de recepção de textos e, obviamente, como corpus textual" (Silva, 1990: 403).

No entanto, como regista Carlos Reis, "Se há disciplina que tenha sido fortemente abalada nos seus alicerces e nas suas convicções por modernas correntes críticas [...], essa disciplina é, sem dúvida, a bistória literária" (Reis, 1981: 63). Com efeito e talvez por isso, a relação desta metalinguagem sobre a literatura (que é a História Literária) com uma outra já mencionada, a da Crítica Literária, tem sido um tanto contraditória, já que "se, por coerência teórica, [a] sua veleidade científica recomendava distância em relação à crítica, nos seus resultados concretos a história da literatura nunca honrou por inteiro o compromisso cientificista de neutralidade axiológica" (Souza, 2014: 58). Operou, portanto, não raras vezes, a partir de

decisões críticas nem sempre declaradas como tal, caso, por exemplo, da exclusão de determinado autor ou obra do conjunto de "fatos" estudados, bem como da variação do grau de atenção concedida aos escritores incluídos, materialmente visível no maior ou menor número de páginas ou linhas dedicadas a cada um nos volumes de história da literatura (Souza, 2014: 58).

Ora, contrariamente ao que se tem observado no campo da literatura dita institucionalizada ou canónica, em relação à qual a periodização literária ganhou relevância, entendida como um dos "modelos de inteligibilidade do processo literário" (Silva, 1990: 404), as singularidades sistémicas da Literatura para a Infância (Shavit, 2003; Weinreich, 2000) parecem ter determinado a relativa desertificação ou a inconsistência da abordagem de que tem sido alvo no domínio da historiografia, sendo, regra geral, ignorados os seus 'pontos nodais' de índole temporal, topográfica, institucional e figurativa (Cunha, 2011).

As considerações tecidas até este ponto decorrem do facto de, em Portugal, e no caso particular da literatura para a infância, a historiografia literária, mesmo contando com algumas abordagens que intentam dilucidar os mais importantes marcos da sua evolução histórica (Lemos, 1972; Pires, 1983; Rocha, 1984/2001; Gomes, 1997; Silva, 2016), representar um campo investiga- 
tivo ostensivamente lacunar. Querer saber mais sobre um autor português e a sua obra de preferencial recepção infantil e juvenil, o seu lugar num contexto evolutivo, por outras palavras, perceber o envolvimento contextual e, simultaneamente, ter acesso a uma visão diacrónica e sincrónica não é, ainda, simples ou imediato, na medida em que continuamos a carecer de uma História da Literatura Infantil e Juvenil Portuguesa.

\section{Maria Cândida Mendonça: algumas razões para o seu lugar na História da Literatura Portuguesa para a Infância}

Maria Cândida Mendonça (1930-1997)² parece ser um exemplo desse grupo de 'femmes oubliées' (Silva e Besse, 2016), fazendo parte desse conjunto de autoras/autores para os quais nem a crítica tem olhado atentamente, nem a historiografia literária tem concedido a merecida atenção, conquanto $\mathrm{Na}$ tércia Rocha, por exemplo, em Breve História da Literatura para Crianças em Portugal (1984/2001), assinale a sua actividade literária, integrando-a "numa nova geração de escritores que se impõe desde os primeiros anos deste período [pós Abril de 1974].” (Rocha, 2001: 101). Acrescenta, também, "Geralmente com actividades literárias já encetadas, a comunicação com o público infantil surge, para estes escritores, como elemento integrado em obra multifacetada" (Rocha, 2001: 101). Neste conjunto de escritores, Natércia Rocha engloba, por exemplo, Luísa Dacosta, António Torrado, Maria Alberta Menéres, Luísa Ducla Soares, Maria Rosa Colaço, Maria Isabel César Anjo, Manuel António Pina, entre outros. Similarmente, José António Gomes, em Para Uma História da Literatura Portuguesa para a Infância e a Juventude (1997), junta o nome de Maria Cândida Mendonça aos de Sidónio Muralha, Matilde Rosa Araújo, Alice Gomes, Papiniano Carlos, Mário Castrim, Carlos Pinhão, Maria Alberta Menéres, Leonel Neves, António José Forte e José Carlos Vasconcelos. Inclui-a no grupo de "autores que contribuíram de forma decisiva para a renovação da poesia para a infância no período 1950-1980" (Gomes, 1997: 61) e deixa anotada a importância de O Livro do Faz-de-Conta. Aliás, já em 1993, no estudo A Poesia na Literatura para a Infância (Asa, 1993), o mesmo investigador tinha dedicado um pormenorizado parágrafo a essa "poetisa de mérito" (Gomes, 1993: 27), como aí a apelida, que, em 1975,

2 Maria Cândida Mendonça nasceu numa aldeia perto de Castelo Branco. Esta informação foi gentilmente facultada por Luísa Ducla Soares. 
publica a obra que acabámos de mencionar-O Livro do Faz-de-Conta-e, onze anos depois, A Cor que se Tem. Acrescenta, igualmente, que os seus poemas "vêm a ganhar uma enorme projecção, ao serem incluídos em inúmeros manuais escolares, tanto do $1^{\circ}$ como do $2^{\circ}$ ciclos do Ensino Básico" (Gomes, 1993: 27).

Talvez a dificuldade de reconstituição do seu percurso biobibliográfico tenha ditado esse relativo apagamento ou contenção nas referências à sua escrita. Pessoalmente, quando decidimos centrar-nos na obra desta autora e procurámos concretizar esse exercício, sem ter como intenção, como se compreende, a assunção de uma perspectiva biografista ${ }^{3}$ ou a valorização do referencial biográfico, em detrimento da concepção de obra como objecto estético, deparámos com uma notória falta de dados.

Ainda assim, os registos patentes na Biblioteca Nacional de Portugal possibilitam delimitar a sua obra literária e algum do seu trabalho, em certa medida, correlato. Sobre este sabemos, por exemplo, que Maria Cândida Mendonça, que foi professora do Ensino Básico e, durante algum tempo, do ensino especial (incluíndo de crianças superdotadas), na década de 80 do século XX, seleccionou e escreveu as notas de uma Colectânea de retratos de Camões, composta por 24 dispositivos e um guia de 30 páginas, bem como de uma outra de Fernando Pessoa (A importância misteriosa de existir), que integra 36 dispositivos e um guia de 34 páginas, ambas publicadas pelo Instituto de Tecnologia Educativa, organismo do Ministério da Educação no qual exerceu funções. Além disso, anos antes, nos finais dos anos 70 e também nos inícios dos anos 80, foi ao-autora, com Luísa Ducla Soares (1939-), com quem se relacionou de forma muito próxima, dos livros escolares Girassol: Leituras para a $2^{a}$ fase $-2^{o}$ ano do ensino primário (Plátano, 1976) e Girassol: fichas de trabalho para a $2^{a}$ fase $-2^{\circ}$ ano do ensino primário (Plátano, 1980). Já nos anos 90 do século XX, assina algumas traduções de volumes da colecção "Começar a ler com Rua Sésamo”, designadamente dos volumes Põe-te boa avózinha! (1992) e Eu quero ir para casa (1992), uma colecção que teve como directora pedagógica Maria Emília Brederode Santos (1942-), outra pessoa com quem lidou de muito perto.

3 Partilhamos, neste ponto, da opinião de Carlos Reis: "A explicação da obra literária numa perspectiva biografista constitui, sem dúvida, a forma mais simplista e linear de tentar penetrar nos meandros significativos do objecto de análise" (Reis, 1981: 64). 
No que diz respeito à sua obra literária, é possível assinalar a existência de um conjunto relativamente restrito -mas interessante- de títulos, uns situados no domínio da narrativa/prosa, em concreto, O Bosque Pintado (1975), A Cidade dos Automóveis (1981) e O Arco-Íris da Amizade (1984), e outros no da poesia, designadamente $O$ Livro do Faz-de-Conta (1975) e $A$ Cor que se Tem (1986), todos publicados com a chancela da Plátano Editora, em colecções que, à data de edição, possuíram um importante papel. A "Caracol”, "A Rã que Ri” e a "Plátano Abril", colecções que, como regista Natércia Rocha, se destacaram pela continuidade, contemplaram volumes escritos por alguns dos mais relevantes autores portugueses para a infância, desempenhando uma função determinante no contacto inicial com a leitura de uma geração de leitores que, no pós-25 de Abril de 74, nas bibliotecas escolares, por exemplo, puderam, assim, conhecer obras que compõem, de facto, um especial acervo, uma particular memória literária. Histórias com fuizo (1973) e Estas São as Letras (1977), ambas de Mário Castrim (1920-2002), e números 9 e 10, respectivamente da colecção "A Rã que Ri”, ou O Trono do Rei Escamiro (1977), de António Torrado (1939-), número 18, da Colecção "Caracol” são alguns desses volumes, vários reeditados já no século XX e tornados, assim, acessíveis a uma outra (nova) geração de leitores.

Inaugurada em 1975 com a narrativa O Bosque Pintado e a colectânea poética O Livro do Faz-de-Conta, a obra literária de Maria Cândida Mendonça é, a vários títulos, merecedora de divulgação e de uma análise em pormenor. Apesar deste estudo ter como objectivo/ideia inicial apenas uma abordagem da sua poesia, optámos por contemplar também uma leitura relativamente breve das suas narrativas (também elas breves), procurando, assim, partilhar uma visão mais lata e desejavelmente mais rigorosa da sua produção literária para a infância. A apresentação seguirá o critério cronólogico, atendendo à data da primeira edição.

O Bosque Pintado (1975), narrativa que é dedicada ${ }^{4}$ a 'Paulo Guilherme', ficcionaliza uma temática recorrente na escrita para a infância da década de 80 do século XX: o ambiente ou o elogio da natureza. Tendo como protagonista a coelhinha Arco-íris, figura antropomorfizada ${ }^{6}$ que convive com o seu

4 As dedicatórias são um denominador comum das obras de Maria Cândida Mendonça.

5 Desconhecemos a identidade deste destinatário, tal como ignoramos também a dos outros a quem Maria Cândida Mendonça dedica os livros posteriores.

6 A antropomorfização ressurge, por exemplo, em vários poemas de O Livro do Faz-de-Conta. 
amigo Mocho Barbatanas, a acção tem lugar no local que o título introduz, espaço natal da personagem mencionada, bem como na cidade, para onde aquela se desloca. $\mathrm{Na}$ figura da personagem principal, a história tematiza a insatisfação com a vida no seio da natureza -Arco-Íris designa o seu Bosque "Bosque Pasmado" -e o desejo (ilusão?) de viver na cidade, de "andar sempre de automóvel" (Mendonça, 1975: s./p.) ou de ir às compras ao supermercado. No entanto, uma breve passagem pela cidade e pelo jardim zoológico, que tinha jaulas com grades duplas, fá-la regressar ao seu Bosque. É nesse "regresso a casa", que a coelhinha percebe como a sua terra é bonita: "Os malmequeres amarelos conversavam com o Sol. / Os nenúfares rosados diziam segredinhos às águas do lado. As faias entoavam canções alegres com as suas vozinhas de prata." (Mendonça, 1975: s./p.).

A força e a diversidade das sugestões cromáticas, combinando com o título da narrativa, associadas aos apontamentos auditivos, às personificações e às metáforas, reflectem o olhar renovado e o entusiasmo da protagonista, ao mesmo tempo que substantivam o elogio da natureza e a liberdade, matrizes temáticas de todo o texto. Estas ideias emergem também significativamente na conclusão do conto: "E, quando apagou a luz, tinha chegado à conclusão que era muito bom estar de volta. No Bosque Pintado não havia jaulas nem guardas, os animais eram livres e as histórias podiam começar duma maneira muito mais bonita - 'Era uma vez...'." (Mendonça, 1975: s./p.).

Assim, vectores ideotemáticos como o elogio da natureza, a liberdade e a amizade perpassam esta narrativa, anunciando já, em certa medida, algumas das isotopias que singularizarão os volumes posteriormente editados por Maria Cândida Mendonça.

As ilustrações de João Machado (1942-) ${ }^{7}$, compostas no registo a que tem habituado o leitor, distinguem-se primeiramente pela suavidade, pela diversidade e pelos contrastes das cores. Ocupando todas as páginas pares do volume, procuram recriar os momentos fundamentais da acção e valorizar a própria protagonista. A sua proximidade com o que diz o texto verbal possibilita uma recomposição da história a partir da sua observação.

7 É licenciado pela Escola Superior de Belas-Artes do Porto, onde foi docente de design gráfico, entre 1976 e 1983, ano em que abandonou o ensino para se dedicar inteiramente ao design. Em 1983, foi $1^{\circ}$ Prémio Nacional Gulbenkian para a melhor llustração de Livros para a Infância. 
O Livro do Faz-de-Conta (1975), volume no 3 da colecção "Plátano de Abril", abre com duas dedicatórias (que rimam): "Este livro é para o João Afonso que o viu escrever / E para todas as meninas e meninos que o quiseram ler.", seguidas de uma epígrafe: "Gente crescida / parece tonta /não entende nada / do faz-de-conta...”. Coligem-se, aqui, vinte poemas criativamente intitulados. Desde o recurso a títulos nominais -como "Adivinha" ou "Espantalho"-, passando por outros que constituem apelativas interjeições -como "Atchim!” ou "Brrr!..."- até aos que possuem um fundo neológico -como as palavras compostas por justaposição "Rato-lagarto" ou "Trovão-Coração"-, estas opções de composição deste elemento paratextual são, por si só, reveladoras do investimento lúdico da autora na sua poesia. Na realidade, todos os textos testemunham um uso criativo do discurso que aqui se encontra ao serviço da tematização de eixos como o elogio da infância, da sua capacidade sonhadora (releia-se, por exemplo, o poema "Folhas") e do seu humor, em oposição aos adultos (veja-se, a este propósito, o poema "Viagem"). A imaginação, por exemplo, é o leitmotiv de textos poéticos como "Folhas" ou "Uma perfeição de cão". Mas existem outros poemas em que se pressente uma visão autoral bastante distinta das mais comuns na época de publicação da colectânea poética em pauta. Referimo-nos, por exemplo, à ideia implícita no texto "Espantalho" de que podemos/temos de alterar o nosso destino e agir por mote próprio, ou, por exemplo, no poema "A Rita sem Fita" que tematiza o faz-de-conta de uma menina que, parecendo afastar-se do 'padrão', brinca aos cowboys, não usa fita, nem vestido bordado.

Além disso, em muitas composições poéticas, são notórias as ressonâncias de formas poético-líricas da tradição literária oral, em concreto de lengalengas, assentes em sequências numéricas, ou das adivinhas, por exemplo, como se constata nos poemas "Atchim!!!"9 e "Adivinha"10, respectivamente. Outros poemas afiguram-se, adoptando aqui a expressão de José António Gomes, estimulantes "historietas em verso" (Gomes, 1993: 27). Veja-se, a título exemplificativo, os poemas "Dia Feriado", "Viagem" ou "O gato Maltês". Outros,

8 De assinalar o facto de $\circ 1^{\circ}$ e o $2^{\circ}$ números desta colecção serem A Pedra Azul da Imaginação (1975), de Maria Alberta Menéres (1930-), e O Jardim Zoológico em Casa (1975), de António Torrado.

9 "Um, dois, três, / era uma vez / um burro sarapintado / de nariz arrebitado. // Quatro, cinco, seis, / o burro teimoso / foi nadar no rio / num dia chuvoso...// [...]" (Mendonça, 1975: 33).

10 "Não é gato / Nem é cão // mas quer caçar ratos / E ser guarda-portão // E tem orelhas e pêlo / Como o leão. // [...]" (Mendonça, 1975: 15). 
ainda, sobressaem, porque se materializam a partir do recurso a originais mecanismos técnico-expressivos. Tome-se como exemplo o poema "A Máscara" (Mendonça, 1975: 41).:

Parei

Espreitei

Entrei

Comprei

Saí

Subi

Abri

Sorri

Peguei

Coloquei

Atei

Ajeitei

Desci

Apareci

Rugi

E ri

Um leão!

Que aflição!!

Mas não

É o João!

Como se observa, trata-se de um texto poético que, formulado na primeira pessoa, se constrói a partir da acumulação de formas verbais no pretérito perfeito, quase todas actanciais, e cada uma delas constituindo um verso de cada uma das quatro quadras, em rima emparelhada e pobre, seguidas de dois dísticos, em rima também emparelhada e em forma exclamativa. Com uma arquitectura bipartida, estipula-se um apelativo jogo de ocultação-descoberta, que, no final, se pauta também pela surpresa e por um certo humor.

Outro exemplo textual do recurso a expressivas estratégias técnico-compositivas corresponde ao poema "Perguntas leva-as o mar...". Neste, sucedem-se seis dísticos interrogativos, quase todos pontuados por um relativo 
nonsense, que parecem testemunhar a curiosidade ou a típica atitude inquiridora de um sujeito de enunciação infantil (Mendonça, 1975: 52):

O peixinho vive no mar por não ter casa para morar?

O mar quando está zangado vê tudo encarnado?

Posso ver uma sereia sentada na areia?

Tem janela e porta a casa da gaivota?

O mar gosta do pescador ou é o seu senhor?

A espuma do mar é para ele se lavar?

Gostava de saber se o mar sabe ler...

E já agora, se faz favor, porque é que o mar muda de cor?

E é um nunca mais acabar de coisas a perguntar acerca do mar...

É também de assinalar a presença, na obra em análise, de alguns poemas visivelmente breves, alguns compostos apenas por uma estrofe. Parecendo resultar de uma "conseguida aliança de simplicidade e poeticidade" (Gomes, 1993: 27), salientem-se os textos poéticos "Brrr..." 11 que contrapõe, com especial sensibilidade, a árvore e a gente, sugerindo a superior resistência da primeira) ou "Ping... Ping... Ping...", no qual se pressente a voz de um sujeito poético cansado do mau tempo e de uma certa subjugação por este imposta (Mendonça, 1975: 54):

11 "Quando a folha cai / a árvore fica nuinha. / Não é como a gente / que diz: / - Chegou o Outono!! / E começa a bater o dente." (Mendonça, 1975: 36). 
Chuva e vento...

Que dia triste!

Apetece fugir

Ir para aquela região

Onde vive o leão

Que não fica fechado

A ver a chuva cair

$\mathrm{E}$ faz o que quer

Faça o tempo que fizer...

Esta obra conta com ilustrações de Romeu Costa ${ }^{12}$ (1944-), que assina igualmente a composição visual de um elevado número de outros volumes publicados pela Plátano editora. Em termos genéricos, graficamente a obra ostenta uma interessante configuração, sendo arquitectada a partir da inclusão de separadores rosa, com o título de cada poema aí inscrito, e a antecederem cada um dos poemas. Além disso, os textos são dispostos seguindo um esquema simétrico (título no separador, título novamente e texto na(s) página(s) seguinte(s)) e nem todos contam com ilustração.

Em 1981, retomando, em certa medida, um dos tópicos-matriz de $O$ Bosque Pintado, Maria Cândida Mendonça lança A Cidade dos Automóveis, narrativa breve, pautada pela simplicidade lexical e sintáctica e que constitui o oitavo número da colecção "Caracol". Como o título propõe cataforicamente, a figura central -chamemos-lhe assim- é um colectivo de automóveis, elemento constante em toda a cidade, que eram, na verdade, os seus donos. A sua presença era manifestamente perturbadora, porque, "Noite e dia, roncavam, buzinavam, fumegavam, atropelavam." (Mendonça, 1981: 2), e as consequências fizeram-se sentir: "Como ninguém dormia, todos foram perdendo a memória a pouco e pouco.” (Mendonça, 1981: 4). Impõe-se, assim, uma pesada desumanização provocada pela invasão/império dos automóveis, uma situação insustentável que apenas se subverte pela acção mágica de um pequeno flautista. É este herói, a quem a autora concedeu poder semelhante ao do alemão de Hamelin -e não deixa de ser curiosa a subtil dimensão intertextual que o texto encerra-, que liberta (desinfesta) a cidade da presença de automóveis e que devolve aos seus habitantes a memória, a amizade e a alegria de

12 Sem possibilidades de confirmar esta informação, cremos que Romeu Costa se trata do escultor português. Romeu Costa nasceu em Lisboa, licenciou-se em Escultura pela ESBAL e foi professor de Artes Visuais no Ensino Básico. 
viver livre de "roncos", buzinadelas, fumos e atropelamentos. A reiteração, precisamente no explicit da narrativa, da segunda frase do seu incipit ("Noite e dia roncavam, buzinavam, fumegavam, atropelavam" (Mendonça, 1981: 2)), acentua a ideia da necessidade de protecção do ambiente para a vida humana, vector ideotemático que, associado a um outro, o da crítica social ${ }^{13}$, se destaca como uma das mais relevantes isotopias da escrita de Maria Cândida Mendonça.

As ilustrações de Carlos Barradas ${ }^{14}$, ocupando as páginas ímpares do volume, procuram, numa linguagem visual que assenta numa paleta de cores ostensivamente limitada, mas que não deixa de ser expressiva, porque, oscilando entre o sombrio e o cinzento e as cores vivas, recria eficazmente a dupla ambiência que distingue o texto: a cidade poluída e a cidade sem carros.

Três anos depois, em 1984, e na mesma colecção, a "Caracol”, Maria Cândida Mendonça retoma a temática da amizade. O Arco-Íris da Amizade é uma original narrativa que abre de forma muito estimulante: "Lembras-te? / O dia começara com um vento forte que abrira de rompão a janela do teu quarto e espantara as pombinhas do papel da parede" (s/p).

Envolvendo, desde logo, através da forma interrogativa, o potencial receptor/leitor infantil que poderá sentir-se o primeiro destinatário do discurso do sujeito de enunciação, na verdade, a narrativa é relatada e dirigida a um destinatário intratextual, também protagonista (infantil) da acção, que é, aliás e num primeiro momento, visualmente introduzido. A matéria narrativa, apresentada em tom evocativo, é constituída pelo relato de um dia da vida da personagem referida -desde o acordar, passando pelo pequeno-almoço, pela sala de aula e pelo recreio ("ao meio-dia"), até à tarde e ao regresso a casa-, bem como por tudo o que vai sentindo e procurando suportar e entender.

Circular e notoriamente simples, a narrativa distingue-se igualmente pela sua configuração simbólica -tenham-se em conta as implicações simbólicas

13 Também já anotado por Gomes, 1993: 27.

14 Carlos Barradas, criador de BD e ilustrador, assinou já um número assinalável de ilustrações de obras preferencialmente destinadas aos mais novos, de autores tão reconhecidos como Maria Cecília Correia (Bom Dia, editado em 1983, pela Plátano), Maria Alberta Menéres (por exemplo, Lengalenga do Vento, publicado em 1976, pela Plátano) ou António Torrado (por exemplo, em 2015, o título Salta para o Saco!, editado pela Caminho). 
dos vocábulos arco-íris, pombinha ou branca-. As angústias e os dilemas infantis, a tristeza, o sentimento de invisibilidade da criança face ao adulto, a incompreensão, a discriminação ou aquilo que hoje (mas que é de todos os tempos) se considera bullying, por exemplo, mas também a solidariedade e a generosidade, o companheirismo ou a amizade ${ }^{15}$ e, muito particularmente, a esperança e essa especial capacidade de superação e de sonhar ${ }^{16}$ que distinguem o tempo e o espaço da infância ganham aqui, no texto de Maria Cândida Mendonça, uma expressão singular, uma expressão reveladora de um conhecimento sensível e profundo do universo em questão. Talvez possamos ser acusados de exagero ou de uma certa extrapolação, mas a verdade é que a obra agora revisitada, por tudo o que mencionámos, poderá situar-se no domínio da literatura de recepção dual.

A composição visual do volume é merecedora de algumas breves notas. A capa e as ilustrações são da autoria de Fred ${ }^{17}$, ilustrador responsável por uma série de sete pequenos desenhos, compostos em técnica mista, cromaticamente contidos ou pouco diversos, nos quais se evidencia o recurso a estratégias muito interessantes que possibilitam uma ampliação semântica dos signos verbais. Referimo-nos, por exemplo, ao facto de, nas ilustrações, o protagonista infantil ser capaz de se pronunciar em discurso directo, aspecto materializado, por exemplo, nos diversos balões de fala que aí são incluídos. Há, ainda, um apontamento que não deixa de se revestir de um discreto sentido de humor: na segunda ilustração, e, em concreto, no jornal que o pai se encontra a ler, pode ler-se o título "Aumento do custo de vida".

A Cor Que Se Tem, colectânea poética datada de 1986, veio lume na colecção “A Rã que Ri” (N²2) da Plátano Editora. Compilação de dezanove poemas, dedicados à 'Ana Filipa'18, nesta retomam-se algumas das temáticas mais assíduas na produção literária de Maria Cândida Mendonça, tópicos ou motivos facilmente reconhecíveis pelo seu potencial destinatário extratextual, o leitor infantil.

15 "Foi então que uma mão pequenina te puxou para baixo dum guarda-chuva e uma vozinha aflita de disse: 'Não chores, não chores, eu sou tua amiga, vem comigo.' / E tu foste." (Mendonça, 1984: s./p.).

16 "E foi como se tivesse deixado de chover para sempre e tu voltaste a ser o grande chefe Pena Branca, o herói da pradaria. / Depois um lindo arco-íris apareceu no céu. / Um arco-íris que só tu viste. / Lembras-te?" (Mendonça, 1984: s./p.).

17 Não foi possível esclarecer a identidade deste ilustrador.

${ }^{18}$ Foi impossível ter conhecimento da identidade do destinatário desta dedicatória. 
Como em alguns dos textos das obras anteriormente analisadas, também nesta se tematizam o sonho (como em "Viagem"), o elogio da natureza, de muitos dos seus elementos (como flores em "Violeta" ou "Girassol", por exemplo) e da vida no seu seio, bem como, em contraponto, se lamenta a vida na cidade e a poluição (como se pode ler em "No solinho da mata" ou "Regresso à cidade"), a amizade (por exemplo, em "O que é?"), o companheirismo e a igualdade. Note-se que muitos poemas não são isentos de crítica social. Revisitem-se, a este título, os poemas "Menina sem Fome" ou "A Senhora Gordinha”, em particular as suas estrofes conclusivas: "Ora, Ana, / se já se viu / uma tolice assim! / Comer só gelados / nem mesmo o pinguim / que até passa fome / lá no meio da neve / e tomara ter / o que a ti não serve." (Mendonça, 1986: 22); "Senhora gordinha, / pense um pouco, / se for capaz, / e veja se entende / que gente magra / pode não ter que comer / não ter alegria / ou paz. / Mas a si tanto lhe faz. // Passe ao largo, senhora gordinha, não queremos nada / com gente tolinha." (Mendonça, 1986: 26).

Também em "A cor que se tem", texto que dá título à colectânea, e em "Mariana, a menina cigana" se elogia ou valoriza a diferença, uma temática que se pode considerar pouco assídua ${ }^{19}$ na poesia portuguesa para a infância da época em que a obra de Maria Cândida Mendonça veio a lume.

Com efeito, em certos poemas que integram a colectânea em apreço, a autora parece não se inibir em ficcionalizar alguns dos eixos ideotemáticos tidos ainda hoje como fracturantes. A diferença e a sua não aceitação, que leva à discriminação ou a comportamentos xenófobos, as desigualdades sociais ou a morte, por exemplo -este último tópico especialmente poetizado no texto "A morte da avó"- surgem substantivados num registo muito pessoal que sabe conjugar o olhar adulto e a visão infantil.

Retomando a perspectiva de Ana Margarida Ramos: "Questionadores e críticos, os [estes] poemas não deixam de se deixar tocar por uma certa tonalidade humorística que também por eles perpassa, a par de uma musicalidade sugerida pelos versos de medida curta, a rima assídua, os paralelismos e as repetições, heranças da lírica de sabor tradicional” (Ramos: s./d.).

\footnotetext{
19 Não ignorando, naturalmente, a sua presença recorrente num número considerável de textos assinados por Luísa Ducla Soares, muitos deles alvo de reedições sucessivas.
} 
As ilustrações da autoria do pintor Francisco Tellechea (Coimbra, 1955-), como se de pequenos quadros se tratassem, destacam-se pela força cromática e pela forma como procuram reproduzir os cenários, as figuras e as temáticas tratadas nos textos.

\section{Considerações finais}

Como procurámos esclarecer, a produção literária de Maria Cândida Mendonça, genologicamente repartida pela narrativa e pela poesia, neste caso, com frequentes ressonâncias das formas poético-líricas da tradição oral, distingue-se não apenas pela originalidade de certas opções técnico-compositivas, mas também, de forma muito acentuada, pela originalidade do seu conteúdo ou dos feixes ideotemáticos que a perpassam. Com efeito, iniciada na década de 70 do século XX, logo no ano imediatamente a seguir ao 25 de Abril, a sua obra versa temáticas inovadoras e, à época, escassamente ficcionalizadas na literatura portuguesa de potencial recepção infantil, designadamente o ambientalismo e/ou o elogio da natureza, associados à crítica social, a valorização da diferença e a infância compreendida solidariamente e tida como valiosa pela sua capacidade imaginativa e sonhadora. Ler e interpretar ou analisar a escrita de Maria Cândida Mendonça é, pois, um gesto indispensável para o conhecimento de uma produção literária que possui um lugar singular na História da Literatura Portuguesa para Infância.

Terminamos, assim, partilhando a convicção que serviu de pilar a este estudo: a formação literária (Souza, 2014: 105)

precisa integrar dois esteios: por um lado, um saber de natureza predominantemente narrativa e concretizante, a história literária, produtora de imagens das literaturas nacionais segundo [as] suas realizações no espaço e no curso do tempo; por outro, a teoria da literatura, um conhecimento de índole universalista e abstratizante, em que, por consequência, em vez da exposição narrativa própria da história literária, predomina o puro manejo dos conceitos.

Por conseguinte, a História da Literatura representa um "fundamento insubstituível para a formação de um especialista em literatura. Mesmo o seu mais duro opositor -acreditamos- há de convir que, sem o domínio de uma espécie de mapa do tempo, é impossível orientar-se no território do literário.” (Souza, 2014: 107). E dessa espécie de mapa do tempo fazem parte 
nomes como -cremos- Maria Cândida Mendonça. A quem disser o contrário propomos um regresso sem pressas ao poema "A cor que se tem" (Mendonça, 1986: 18):

Quando for crescida

hei-de inventar

um perfume de encantar.

Quem o cheirar

há-de ficar

com a cor de pele

que mais gostar.

Branco ou amarelo

se preferir

preto ou vermelho

é só decidir.

Para alegrar

até estou a pensar

outras cores acrescentar.

88

Cor-de-rosa

verde ou lilás

são cores bonitas

e tanto faz.

E assim

há-de chegar

o dia de acreditar

que o valor

de alguém

não se pode avaliar

pela cor

que tem.

E então

tudo estará bem. 


\section{Referências bibliográficas}

\section{Bibliografia ativa}

Mendonça, Maria Cândida. 1975²0. O Livro do Faz-de-Conta. Colec. "Plátano de Abril”, nº 3. Lisboa: Plátano Editora (ilustrações de Romeu Costa).

Mendonça, Maria Cândida. 1975. O Bosque Pintado. Lisboa: Plátano Editora (ilustrações de João Machado).

Mendonça, Maria Cândida. 1981. A Cidade dos Automóveis. Colec. "Caracol", nº 8. Lisboa: Plátano Editora (capa e ilustrações: Carlos Barradas).

Mendonça, Maria Cândida. 1984. O Arco-Íris da Amizade. Colec. "Caracol", nº 22. Lisboa: Plátano Editora (capa e ilustrações: Fred).

Mendonça, Maria Cândida. 1986. A Cor Que Se Tem. Colec. "a rã que ri”, nº 22. Lisboa: Plátano Editora (ilustrações de Francisco Tellechea).

\section{Bibliografia passiva}

Compagnon, Antoine. 2010. Para Que Serve a Literatura?. Porto: Deriva.

Cunha, Carlos Manuel F. da. 2011. "A História Literária no Século XXI". Em Pensara Liter@tura no Séc. XXI ( orgs. José Amadeu Silva, José Cândido Martins e Miguel Gonçalves). Braga: Publicações da Faculdade de Filosofia-Universidade Católica Portuguesa, pp. 299-305.

Equipo Glifo. 1998. Diccionario de termos literarios. Vol. E-h. Santiago de Compostela: Centro Ramón Piñeiro para a Investigación en Humanidades/Xunta de Galicia.

Gomes, José António. 1993. A Poesia na Literatura para a Infância. Porto: Asa.

Gomes, José António. 1997. Para uma História da Literatura Portuguesa para a Infância e a fuventude. Lisboa: MC-IPLB.

Lemos, Esther. 1972. A Literatura Infantil em Portugal. Lisboa: MEN-DGEP.

20 volume não possui a indicação da data de publicação. As referências que encontrámos em (Gomes, 1993) e (Gomes, 1997) fixam 1975 como ano da primeira edição. No catálogo da Biblioteca Nacional de Portugal, existe um exemplar deste título com a data de 1979. 
Lemos, Esther. 1973. "Infantil, literatura”. Em Dicionário de Literatura, v. 1 (org. Jacinto do Prado Coelho). Porto: Figueirinhas, pp. 467-475.

Pires, Maria Laura Bettencourt. 1983. História da Literatura Infantil Portuguesa. Lisboa: Vega.

Ramos, Ana Margarida. s./d. A cor que se tem (recensão), em http://www.casadaleitura.org/portalbeta/bo/portal.pl?pag=sol_li_fichaLivro\&id=1754 [Consulta: 20/10/2016].

Reis, Carlos. 1981. Técnicas de Análise Textual. Coimbra: Almedina.

Rocha, Natércia. 2001. Breve História da Literatura para Crianças (Nova edição actualizada até ao ano 2000). Lisboa: Caminho.

Roig Rechou, Blanca (coord.). 2016. Historia da Literatura Infantil e Xuvenil Galega. Vigo: Xerais.

Shavit, Zohar. 2003. Poética da Literatura para Crianças. Lisboa: Editorial Caminho.

Silva, Maria Araújo da e Besse, Maria Graciete (orgs.). 2016. Femmes Oubliées dans les Arts et les Lettres au Portugal (XIXe.-XXe. Siècles). Paris: Indigo-Côté Femmes.

90 Silva, Sara Reis da. 2016. Capítulos da História da Literatura Portuguesa para a Infância. Porto: Tropelias \& Companhia.

Silva, Vítor Aguiar e. 1990. Teoria da Literatura. Coimbra: Almedina (8 ${ }^{\text {a ed.). }}$

Souza, Roberto Acízelo de. 2014. História da Literatura. Trajetória, fundamentos, problemas. São Paulo: Realizações Editora.

Villanueva, Darío. 1994. Avances en Teoría de la Literatura (Estética de la Recepción, Pragmática, Teoría Empirica y Teoría de los Polisistemas). Santiago de Compostela: Universidade de Santiago de Compostela.

Villanueva, Darío. 2004. “O estatuto actual da crítica literária”. Em Elementos de Crítica Literaria (coord. Arturo Casas), colec. Universitaria, série Manuais, nº 10, Vigo: Xerais, pp. 17-38.

Weinreich, Torben. 2000. Children's Literature - Art or Pedagogy?. Copenhaga: Roskilde University Press. 